\title{
LEITURA DELEITE COMO ANCORAGEM PARA MUDANÇAS PEDAGÓGICAS NO ÂMBITO DO PNAIC
}

\author{
LA LECTURA DE PLACER COMO ANCORAJE PARA CAMBIOS EN LA \\ ENSEÑANZA EN CONTEXTO DEL PNAIC
}

\section{PLEASURE OF READINNG AS ANCHORAGE FOR EDUCATIONAL CHANGES IN PNAIC SCOPE}

\author{
Geisa Magela VELOSO ${ }^{1}$ \\ Úrsula Adelaide de LÉLIS ${ }^{2}$ \\ Cecídia Barreto ALMEIDA ${ }^{3}$
}

RESUMO: Trata-se de um estudo quali-quantitativo, que tem por objetivo analisar representações de professoras sobre conteúdos e estratégias formativas propostas pelo Pacto Nacional pela Alfabetização na Idade Certa/PNAIC, captando o seu enraizamento na cultura escolar por meio dos processos de objetivação e ancoragem. A análise da realidade indica uma prevalência da leitura deleite como prática voltada para o prazer de ler e a dinamização das atividades na sala de aula, em contraposição ao obscurecimento da alfabetização nas representações das professoras participantes do estudo.

PALAVRAS-CHAVE: Alfabetização. Letramento. Leitura deleite. Cultura escolar. PNAIC.

RESUMEN: Se trata de un estudio cualitativo y cuantitativo, cuyo objetivo es analizar las representaciones de los docentes en contenidos y estrategias de formación propuestos por el Pacto Nacional pela Alfabetização na Idade Certal PNAIC (Pacto Nacional para la Alfabetización en la Edad Correcta), la captura de su enraizamiento en la cultura escolar a través de los procesos de objetivación y ancoraje. Los análisis indican una prevalencia de la lectura de placer ya la práctica dirigida por el placer de la lectura y la promoción de actividades en el aula, en oposición al oscurecimiento de la alfabetización en las representaciones de los profesores participantes en el estudio.

PALAVRAS CLAVE: Alfabetización. Alfabetismo. La lectura de placer. Cultura escolar. PNAIC.

ABSTRACT: It is a qualitative and quantitative study, which aims to analyze representations of teachers on content and formation strategies proposed by the Pacto Nacional pela Alfabetização na Idade Certal PNAIC, capturing his rooting in the school culture through the processes of objectification and anchoring. The reality of the

\footnotetext{
${ }^{1}$ Doutora em Educação pela Universidade Federal de Minas Gerais/UFMG; Professora da Universidade Estadual de Montes Claros/Unimontes. velosogeisa@gmail.com

${ }^{2}$ Doutora em Educação pela Universidade Federal de Uberlândia/UFU; Professora da Universidade Estadual de Montes Claros/Unimontes. ursulalelis@gmail.com

${ }^{3}$ Mestre em Educação pela Universidade de São Marcos; Professora da Universidade Estadual de Montes Claros/Unimontes. cecidiaba@gmail.com
} 
analysis indicates a prevalence of pleasure of reading as focused practice for the pleasure of read and the diversify of activities in the classroom, as opposed to obscuration of reading instruction in the representations of the study participants teachers.

KEYWORDS: Reading instruction. Literacy. Pleasure of Reading. School culture. PNAIC.

\section{Introdução}

No momento atual, em que se ampliam as necessidades sociais de uso da leitura e escrita, tem sido reforçada a responsabilidade da escola, que precisa produzir mediações pedagógicas para garantir a alfabetização e o letramento. Tais mediações devem favorecer a imersão das crianças na cultura escrita, de forma que possam aprender a ler e a escrever, mas, também, envolver-se em práticas sociais de leitura e escrita de diferentes gêneros textuais (SOARES, 1998). É grande a variedade de situações sociais que exigem o uso da leitura e da escrita, demandam a capacidade de redigir textos, de ler e produzir significações para os textos lidos, de acessar informações, utilizar a leitura e a escrita para resolver problemas.

Neste contexto, em que oceanos de informação são disponibilizados pelas ferramentas tecnológicas, Perroti (2002) discute a democratização dos bens culturais, considerando que, no caso da cultura escrita, se faz necessário o acesso aos produtos culturais - jornais, revistas, livros, etc -, mas também aos instrumentos socioculturais e cognitivos essenciais à construção do conhecimento, dos sentidos e significados inscritos nesses objetos culturais.

Para atender a tais exigências, o Ministério da Educação (MEC) criou, em 2012, o Pacto Nacional pela Alfabetização na Idade Certa (PNAIC), política de formação continuada em serviço de professores alfabetizadores, implementada por universidades públicas a partir do ano subsequente, junto às escolas estaduais e municipais de mais de 5.000 municípios.

No Brasil, o campo da alfabetização e do letramento fomentou a implementação e consolidação de políticas de formação de professores, sendo que, a partir da década de 1980, os sistemas de ensino e as universidades vêm fortalecendo o debate sobre os desafios da alfabetização, discutindo paradigmas, formas de organização da escola nos anos iniciais, bem como conteúdos e materiais didáticos voltados ao ensino inicial da 
leitura e da escrita. Alguns movimentos e processos de formação de professores provocaram mudanças ora contingenciais, ora orgânicas, impondo, inclusive, novas temáticas para a pesquisa acadêmica, orientando o investimento e a implementação de políticas públicas que sustentem tal processo.

O PNAIC fundamenta-se na necessidade de se levar em conta o tempo e a natureza da criança, seus interesses e especificidades, por um movimento em que a ludicidade consitui-se como um dos eixos para a ação educativa. Também considera que aprender a ler e escrever - alfabetização - se constitua como direito inalienável das crianças, sendo este um processo paralelo e indissociável à sua inserção no universo da cultura escrita - letramento.

Nos processos de formação, a apropriação do sistema de escrita alfabética e o desenvolvimento das habilidades de leitura e escrita constituíram-se como objetos sistemáticos de reflexão, de forma a garantir a análise das práticas alfabetizadoras e produzir as mudanças pedagógicas necessárias ao atendimento aos direitos de aprendizagem das crianças. Nos seminários, a leitura deleite, compreendida pelo PNAIC como importante estratégia formativa, constituiu-se como prática permanente, como momento de prazer e reflexão sobre o que é lido, sem se preocupar com a questão formal da leitura. Trata-se de ler para se divertir, sentir prazer, refletir sobre a vida, sem, no entanto, excluir situações em que se conversa sobre os textos, como fruição e ampliação de saberes (BRASIL, 2012b, p. 29).

Neste cenário, este artigo tem por objetivo analisar representações de professoras sobre conteúdos e estratégias formativas propostas pelo PNAIC, captando o seu enraizamento na cultura escolar por meio dos processos de objetivação e ancoragem. Entendemos, com Moscovici (1978), que as representações são constituídas por duas faces indissociáveis, a figurativa e a simbólica, para integrar novos objetos ao universo do sujeito. Tais processos são denominados pelo autor de objetivação e ancoragem. A objetivação relaciona-se a imagens construídas para tornar concreto e presente o objeto representado; a ancoragem corresponde à constituição de sentido a uma imagem, um mecanismo pelo qual se pode transformar em familiar o insólito, ou o insólito em familiar, mudar o universo sem que ele deixe de ser o nosso universo. Assim, pela ancoragem, o sujeito pode atenuar as estranhezas, buscar categorias e imagens conhecidas para transformar o que é estranho em algo familiar. 
Neste contexto, com a finalidade de captar mudanças produzidas nas práticas das professoras alfabetizadoras ${ }^{4}$, foi desenvolvida pesquisa de natureza quali-quantitativa, por pesquisadoras que integraram a equipe de formação do PNAIC na Universidade Estadual de Montes Claros (UNIMONTES). A nossa dupla implicação no processo, como formadoras e pesquisadoras, exigiu um esforço analítico, de forma a ultrapassar nossas próprias práticas e representações e produzir o necessário distanciamento críticoreflexivo em relação aos dados.

Pela pesquisa procurou-se mapear conteúdos e estratégias formativas propostos pelo PNAIC, desenvolvidos nos processos de formação pela universidade e indicados pelas professoras como orientadores de suas ações cotidianas em sala de aula. $\mathrm{O}$ processo de coleta de dados constituiu-se na resposta a um questionário impresso, aplicado pelos orientadores de estudo, aos 3.152 professores bolsistas, vinculados à rede pública de ensino de 119 municípios do Vale do Jequitinhonha, das regiões norte e central de Minas Gerais, participantes do PNAIC/Unimontes, entre os meses de novembro e dezembro de 2015. Deste universo, 1002 sujeitos responderam ao questionário e constituem a amostra desta pesquisa.

As análises encontram-se organizadas em três seções que compõem este artigo. Na primeira, apresenta-se o discurso oficial do PNAIC, que propôs a leitura deleite como estratégia formativa e gerou sua inserção nas turmas de alfabetização. Na segunda, analisa-se o modo como a leitura deleite foi apropriada pelas alfabetizadoras, ancorando-se nas práticas cotidianas para dinamizar as aulas e produzir nos alunos o prazer de ler. Por fim, discute-se o obscurecimento da alfabetização nas representações das professoras, evidenciado pela baixa visibilidade para a apropriação da escrita alfabética nos discursos analisados.

\section{O discurso oficial: a leitura deleite como proposição do PNAIC}

Para analisar as contribuições do PNAIC na formação das professoras, orientamo-nos pela crença na possibilidade de mudanças conceituais e didáticas que possam refletir sobre a sua ação pedagógica em sala de aula. Ao tomar a leitura deleite e a apropriação do sistema de escrita alfabética como objetos de estudo, procuramos

\footnotetext{
${ }^{4}$ Nesse texto, ao referimos aos sujeitos do estudo, optamos por utilizar a expressão "professoras", dada a prevalência das mulheres no exercício da profissão docente e da função alfabetizadora nas escolas.
} 
compreender a cultura escolar em suas mudanças e permanências, considerando os processos de objetivação e ancoragem produzidos pelas professoras. Entendemos, com Julia (2001), que o conceito de cultura escolar descreve um conjunto de normas que definem conhecimentos a ensinar e condutas a inculcar, como também de práticas que permitem a transmissão desses conhecimentos e a incorporação desses comportamentos, por um processo em que normas e práticas se apresentam coordenadas às finalidades da ação educativa.

Por uma abordagem histórica das culturas escolares, Julia (2011, p.23) afirma que, no século XIX, a instrução primária obrigatória, em diferentes países da Europa, orientou-se por finalidades atribuídas à escolarização e, frequentemente, se construiu ligada a um projeto político, que visava associar a cada cidadão o destino da nação à qual pertence. "Não se trata somente de alfabetizar, trata-se de forjar uma nova consciência cívica por meio da cultura nacional e por meio da inculcação de saberes associados à noção de "progresso"”. Para o autor, o estabelecimento desta nova escola primária não se realizou pacificamente, posto que, no momento em que uma nova diretriz redefine finalidades, os antigos valores não são eliminados, as antigas divisões não são apagadas, mas novas restrições somam-se às antigas.

$\mathrm{Na}$ contemporaneidade, percebe-se a centralidade da alfabetização como finalidade atribuída às escolas brasileiras. Isso porque o Brasil ainda convive com a não alfabetização plena de muitas crianças, que concluem a escolarização sem se apropriarem de conhecimentos e habilidades esperados. Consta no Caderno de Apresentação que as ações de formação sejam ferramentas que visam garantir o direito de alfabetização plena de meninos e meninas, até o $3^{\circ}$ ano de escolaridade. Mais do que apropriar-se do sistema de escrita, a alfabetização implica “[...] ampliação do universo cultural das crianças, por meio da apropriação de conhecimentos relativos ao mundo social e da natureza" (BRASIL, 2012a, p. 26).

No PNAIC, considerando a necessária estabilidade dos processos formativos, o Caderno de Formação sugere estratégias permanentes, a serem desenvolvidas na formação: leitura deleite; tarefas de casa e escola; estudo dirigido de textos; planejamento de atividades a serem realizadas nas salas de aulas; socialização de memórias; vídeo em debate; análise de situações de aula filmadas ou registradas, de atividades de alunos, de relatos de rotinas, de sequências didáticas e projetos didáticos, planejamentos de aulas, de recursos didáticos; exposição dialogada; elaboração de 
instrumentos de avaliação e discussão de seus resultados; avaliação da formação (BRASIL, 2013b).

Em nosso estudo, inspiradas em discussões de Julia (2001), procuramos ultrapassar o nível das prescrições/proposições inscritas nos materiais e nos processos de formação do PNAIC para compreender os usos que as professoras fizeram destes modelos que lhes foram impostos/propostos e dos objetos que lhes foram distribuídos. Isso porque, no estudo das culturas escolares, não se pode tomar as ideias como práticas efetivas, posto que o prescrito nem sempre se materializa em atos ou comportamentos. Para Julia (2001), torna-se necessário ampliar o foco de análise para superar a idealização dos discursos oficiais e construir uma visão mais realista da escola, para compreender as práticas, os dispositivos didáticos produzidos pelos professores, as táticas de transgressão e as resistências ao estabelecido.

Considerando que o PNAIC é uma política pública de governo e, portanto, não tem garantia de implementação, efetivação e continuidade junto às escolas, procuramos captar transformações que, para além do tempo imediato, pudessem ser mantidas, constituindo-se como parte dos fazeres das professoras, mas, também, elementos que ainda não se constituíram na cultura escolar e que demandam novas intervenções por parte do Programa.

Ferreira (2012b) analisa que, muitas vezes, a formação continuada se encontra inserida em um discurso institucional que obriga os professores a participarem de programas. E, assim, dependendo do modo como são propostas as atividades, eles poderão integrar-se aos processos de modo ativo, ou não. Portanto, não é a obrigação, mas "o engajamento de modo ativo que promove a transformação do fazer pedagógico cotidiano" (2012b, p. 12).

Ainda conforme a autora, os professores em processo de formação continuada possuem um saber sobre sua profissão, que precisa ser valorizado e não desconsiderado. Mas, é preciso que os professores compreendam que esse conhecimento já adquirido não é estático, pode ser modificado, melhorado, trocado, ratificado, reconstruído, refeito ou abandonado.

Em nosso estudo, para captar as apropriações do PNAIC, foi solicitado às professoras que listassem os conteúdos abordados no processo de formação que, mais diretamente, orientam sua prática atual. As análises nos permitiram constatar que as professoras alicerçam sua atividade pedagógica em saberes construídos no decurso de sua trajetória. Contudo, as ações de formação produziram o rompimento com elementos 
da cultura escolar já instaurada e materializada, pela inserção de atividades que as professoras consideram como inovação.

As respostas indicam que as professoras produziram um movimento interpretativo do PNAIC, incorporando sugestões e proposições oriundas dos seminários de formação. Dentre as 1.002 professoras participantes do estudo, obtivemos um total de 1.410 indicações de conteúdos e/ou atividades orientadores das práticas. As respostas que remetem para conteúdos que dialogam com o campo da alfabetização linguística com maior incidência, foram: $92(9,1 \%)$ que indicam a importância da interdisciplinaridade no ciclo de alfabetização; $103(10,27 \%)$ que sinalizam as brincadeiras; $262(26,14 \%)$ que afirmam os jogos como conteúdo relevante; 235 $(23,45 \%)$ que destacam a leitura deleite; enquanto que o conteúdo sequências didáticas foi indicado por $270(26,94 \%)$ professores.

Outra indagação sobre atividades e metodologias do PNAIC, que as professoras acreditam que continuarão a desenvolver em sala de aula, que visou captar a estabilidade das mudanças operadas/materializadas na cultura escolar, gerou 3.307 respostas. Os itens que obtiveram maior incidência, que indicam a intencionalidade de realização frequente, são: atividades interdisciplinares, com 109 indicações (10,87\%); atividades de socialização e de integração entre as crianças, com 112 marcações $(11,17 \%)$; brincadeiras, com $520(51,89 \%)$ respostas; sequências didáticas, com frequência de 587 (58,58\%); e jogos pedagógicos, com 673 (67,16\%) indicações. No entanto, a atividade recordista foi a leitura deleite, apontada por 707 professoras (70,55\%), que pretendem utilizar-se desta estratégia com seus alunos.

No âmbito do PNAIC/Unimontes, a leitura deleite foi apropriada pelas formadoras, encontrando espaço de vivência e experiência nos processos formativos, sendo realizada, sobretudo, pela leitura compartilhada de histórias. Nas rodas de leitura foram utilizados livros digitalizados projetados por meio de equipamento multimídia opção que possibilitou explorar as potencialidades das obras, no formato proposto por seus autores e ilustradores.

Referenciadas pelas orientações e princípios propostos pelo MEC, como equipe de coordenação e formação do PNAIC na Unimontes, colocamos foco na leitura deleite, que foi apresentada aos alfabetizadores como prática a ser realizada diariamente com as crianças. E, ao fazê-lo, pretendíamos criar condições para ampliar o repertório literário das professoras, favorecer oportunidades para conhecerem autores e obras destinadas ao público infantil, desenvolver sua sensibilidade estética e apreciação da linguagem 
literária. Tais vivências serviram ao processo de objetivação da leitura literária e integração do desconhecido - "leitura deleite" - em práticas familiares às professoras leitura compartilhada de textos, atividades no Cantinho de Leitura e rodas de contação de histórias. Desta forma, foram produzidos processos de objetivação em que a leitura deleite foi alçada à condição de atividade casa-escola, com realização diária obrigatória junto às crianças. E, "ao assim o fazer, sujeitos sociais ancoram o desconhecido em uma realidade conhecida e institucionalizada" (JOVECHELOVITCH, 1995, p. 82).

Ao apropriarmo-nos da leitura deleite, propondo/impondo sua realização diária junto às crianças, ancoramo-nos em Neitzel (2007), ao afirmar que a leitura esporádica ou realizada com frequência semanal não é suficiente para consolidar hábitos culturais e criar afinidades entre a criança e os textos. Apoiamo-nos na crença de que, como mediadores, os professores podem se tornar elos fundamentais, por indicar leituras e abrir espaços para o livro. Fundamentados em Brito (2009), estávamos convencidas de que, para as crianças que ainda não sabem ler, os professores podem possibilitar sua entrada no mundo da cultura letrada, por um modo especial de ler com os ouvidos. Isso porque, "quando uma criança de, por exemplo, 3 anos, toma emprestada a voz da mãe, da professora, da amiga, e lê o texto com a voz emprestada, ela está lendo. Está lendo com os ouvidos, assim como os outros leem com os olhos ou com as mãos" (2009, p.xiii).

Pelas rodas de leitura e o compartilhamento de histórias, podem propiciar a entrada da criança no universo ficcional, desenvolver sua sensibilização, despertar seu desejo por livros, favorecer a vivência de experiências estéticas com a linguagem e a fruição da arte literária. Podem favorecer, ainda, o conhecimento acerca das especificidades da linguagem escrita, suas convenções e regras, a familiarização com a estruturação dos diferentes gêneros textuais escritos. Segundo Brito (2007), ler com os ouvidos pode permitir à criança experimentar a cultura escrita, inserir-se na interlocução com o discurso típico dos gêneros escritos, que se organizam por uma sintaxe, um léxico e uma prosódia diferentes da linguagem oral cotidiana.

Pela crença no poder da literatura, Barthes (1989) afirma que sua escolarização precisa ser modificada, sofrer correções para que os professores possam manter um discurso sem imposição, "pois o que pode ser opressivo no ensino não é finalmente o saber ou a cultura que ele veicula, são as formas discursivas através das quais ele é proposto" (1989, p. 43). 


\section{Discursos e práticas docentes: ancoragem e objetivação da leitura deleite}

Diferentes autores defendem que, desde os primeiros meses de vida, a leitura compartilhada, a contação de histórias e o manuseio de livros são essenciais à formação das crianças. Ao discutir a influência das rodas de contação de história para bebês, entre 6 meses e 3 anos de idade, Neitzel (2007) destaca aprendizagens possíveis a partir desta prática: acelera o desenvolvimento linguístico das crianças; possibilita a construção de uma rede conceitual; permite construir sentidos e ampliar a comunicação com o mundo real, descobertas e compreensão de mundo, refinamentos e acréscimos conceituais, criatividade e criticidade.

Ao fazer a defesa da leitura de literatura na escola, Albergaria (2000) afirma ser o texto ficcional uma necessidade do leitor e que todos precisam de recolhimento, silêncio e momentos de solidão para exercer suas faculdades imaginativas. A grande vantagem da literatura em relação aos demais gêneros textuais é que o texto literário contribui para formar o leitor mais hábil, porque este não é fechado e, assim, para além do prazer, abre espaço para a negociação de sentidos, para a participação do leitor (ALBERGARIA, 2000).

No processo representacional das professoras participantes deste estudo, as práticas de contação de histórias, o Cantinho de Leitura e a leitura compartilhada serviram à objetivação, conferindo materialidade para a estratégia formativa da leitura deleite, cumprindo a função de aproximar as crianças dos livros literários e despertarlhes o gosto por histórias. Nos seus discursos, essa prática serviu, também, ao propósito de tornar as aulas dinâmicas e divertidas:

Dinamizar aulas e prazer do aluno. Jogos e brincadeiras, leitura deleite, aprendi a dinamizar minhas aulas, pois assim as crianças aprendem mais (PROFESSORA DA REDE MUNICIPAL PESQUISA 2015).

A introdução da contação de histórias, jogos e brincadeiras tornou as aulas mais ricas, menos cansativas e mais produtivas (PROFESSORA DA REDE MUNICIPAL - PESQUISA 2015).

É importante ressaltar que uma rotina de trabalho direcionada com histórias, jogos e atividades criativas e variadas colaboram para o sucesso dos alunos (PROFESSORA DA REDE MUNICIPAL PESQUISA 2015).

Para entender a objetivação e ancoragem da leitura deleite nas práticas das 
professoras, fundada na defesa do prazer do aluno e na diversificação de metodologias, é importante retomar o contexto histórico em que se produziram discursos a favor da renovação das práticas educativas. Isso porque, a análise dos processos de objetivação e ancoragem “[...] permite compreender como o funcionamento do sistema cognitivo interfere no social e como o social interfere na elaboração cognitiva" (ALVESMAZZOTTI, 1994, p. 63). Ancorar é classificar e rotular, tornar familiar o que é estranho e ameaçador; é promover o enraizamento social da representação, é construir uma rede de significados em torno do objeto, realizar a sua integração cognitiva ao sistema de pensamento já existente (JOVECHELOVITCH, 1995).

Por essa compreensão, podemos inferir que os discursos das professoras têm suas raízes nos princípios da Escola Nova. No Brasil, o movimento escolanovista ganhou visibilidade a partir da década de 1930, e promoveu a negação do processo verbalista de transmissão de conhecimento, colocando foco sobre a diversificação de estratégias didáticas na ação educativa. Estudos de Vidal (2001) mostram que, já na década de 1920, Fernando de Azevedo e Anísio Teixeira posicionaram-se em defesa da renovação da escola brasileira, em que os processos educativos se orientassem por uma nova concepção de ensino, centrada na atividade, sendo que o desejo, o interesse e o prazer da criança se constituíram como molas propulsoras desta atividade. Neste contexto, a autora também destacou a importância assumida pelo livro que, de depositário da cultura universal, passou a ser visto como fonte de experiência. No entanto, como lembra Vidal (2001), o discurso escolanovista não se ocupou apenas em normatizar o livro, atentando para seu aspecto material e de conteúdo.

Uma explosão de falas sobre a leitura apontava para uma nova sensibilidade. A leitura prazerosa, muitas vezes identificada com a literatura, poderia ser reencontrada no trabalho e na escola. Abolido o livro-texto, a que se escravizavam os escolares, despertar-se-ia no aluno novo prazer por ler: aventura intelectual. Uma pluralidade de textos oferecia-se à descoberta (VIDAL, 2001, p. 207-208).

Por influência dessas concepções sobre o livro e a leitura, ainda hoje, a fruição, o entretenimento e a leitura prazerosa encontram ressonância nas escolas e nas práticas docentes. No âmbito do PNAIC, o prazer e o interesse dos alunos passaram a ancorar as práticas da leitura deleite e nos permitiram compreender posicionamentos das professoras: 
Inseri no meu planejamento de sala de aula a leitura deleite e jogos de forma variada, com isso a criança tem mais prazer em estar em sala de aula (PROFESSORA DA REDE MUNICIPAL - PESQUISA 2015).

Gosto pela leitura e aprendizagem. As crianças despertaram gosto pela leitura. Interessam-se mais pelas aulas (PROFESSORA DA REDE MUNICIPAL - PESQUISA 2015).

A leitura deleite que é feita diariamente na sala de aula e de suma importância para despertar o gosto pela leitura (PROFESSORA DA REDE MUNICIPAL - PESQUISA 2015)

Os discursos das professoras revelam representações altamente positivas da literatura, das rodas de contação de histórias, da prática de leitura compartilhada, dos Cantinhos de Leitura, da utilização da literatura como exercício para fruição da linguagem. Os livros literários e a leitura são vistos como recursos para atrair a criança e nela despertar o prazer pela leitura, favorecendo aprendizagens. O ler pelo prazer de ler, tornou-se uma escolha didática concreta, no cotidiano da sala de aula, capaz de estimular a criatividade, desenvolver o imaginário das crianças, contribuir para compreensão leitora - o que remete à percepção de que a escola, nesta perspectiva, constitui-se como principal agência de letramento literário.

Pela proposição da leitura deleite, inferimos que o PNAIC contribuiu para que os acervos de obras literárias e apoio pedagógico, jogos e tecnologias educacionais, distribuídos pelo MEC, cumprissem sua finalidade - conduzir professores e alunos a se aproximar das obras, construir uma relação de pertencimento e de intimidade com os livros, desenvolver o gosto por leituras, descobrir o prazer de ler. No entanto, para além do hábito e do prazer de ler, a literatura está investida de inúmeras possibilidades de aprendizagem sobre a linguagem escrita, nem sempre percebidas pelas professoras e não abordadas ou enfatizadas pelo PNAIC.

Nos discursos analisados, constatamos que as professoras percebem algumas possibilidades de aprendizagem inscritas na literatura infantil.

Está sendo positivo e prazeroso. As crianças tornaram-se leitoras assíduas, descobrindo o mundo mágico que a leitura nos proporciona, sem contar, que, com certeza falarão e escreverão com clareza e autonomia. Enfim, o Pacto veio somar, tornar prazerosa e enriquecedora as nossas experiências (PROFESSORA DA REDE MUNICIPAL - PESQUISA 2015).

E a leitura deleite, além de despertar nos alunos, a vontade de ler, conduz o aluno à desinibição, gerando atitudes extremamente positivas (PROFESSORA DA REDE MUNICIPAL - PESQUISA 2015). 
Onde os alunos estão descobrindo que a leitura é uma deliciosa viagem. Aprendendo a falar sobre o que sabem, usando melhor as palavras e transmitindo suas ideias com clareza e, assim, aos poucos, percebem o quanto tudo isso é importante para se tornarem cidadãos conscientes de seus deveres e de seus direitos (PROFESSORA DA REDE MUNICIPAL - PESQUISA 2015).

Ao fazerem a defesa da leitura, as professoras tomam a literatura como possibilidade para a ampliação de saberes sobre a linguagem escrita. No entanto, como formadoras de professores, identificamos nesses discursos dois pontos sobre os quais precisamos lançar nosso olhar perscrutador. De um lado, a presença dessa argumentação está presente em um número reduzidíssimo de professoras. Por outro lado, há nos discursos uma abordagem pragmática, que limita as possibilidades formativas da literatura infantil - fato que demanda investimentos de formação, de modo que se possa ampliar as percepções e gerar mudanças mais consistentes nas salas de aula. Isso porque, pela via da literatura, para além do sonho, da imaginação e do devaneio, é possível que o leitor compreenda os recursos expressivos utilizados por seu autor, ultrapassando o nível da leitura fácil para atingir o nível da abstração e da leitura crítica, somente possível ao leitor investigativo, ávido por entrar no texto e deslizar por outros tempos e lugares (NEITZEL, 2007). Albergaria (2000) considera que o texto literário provoca reflexão e estranhamento, contém um desafio maior do que outros textos, pode levar a outros conhecimentos e conteúdos. Neste sentido, o autor acredita que o leitor literário é um leitor mais completo e, portanto, mais apto a se tornar um cidadão pleno.

Em nosso estudo, ao procurar compreender o porquê desta ausência da literaridade dos textos nos discursos das professoras, deparamo-nos com lacunas do próprio PNAIC. Isso porque, no âmbito da formação, a leitura deleite foi proposta como estratégia formativa (BRASIL, 2012b) e, com este status, o letramento literário foi invisibilizado nos cadernos do Programa. Na perspectiva dos processos de formação, a leitura deleite apresentou-se como prática, mas a literatura infantil não encontrou espaço para ser teoricamente discutida, de forma que os professores pudessem ampliar sua visão sobre possibilidades e especificidades do letramento literário, sobre sua potencialidade para a alfabetização das crianças.

\section{O obscurecimento da alfabetização nas representações das professoras}


Garantir uma consistente alfabetização, com consequente inserção das crianças em práticas sociais de leitura e escrita é o objetivo do PNAIC, para o qual as práticas de leitura compartilhada de histórias têm muito a contribuir. Daí a relevância da leitura deleite, cujas práticas podem produzir a familiarização das crianças com a cultura escrita, favorecer-lhes condições para usufruir do livro literário como objeto cultural. Em nosso estudo, ao dar voz às professoras alfabetizadoras, captamos apropriações e mudanças operadas, mas, também, permanências em seu sistema de significação. Foi possível perceber que, de um lado, as práticas docentes colocaram em circulação os livros literários, produzindo um ciclo em que as histórias ganharam visibilidade nas escolas. Mas, por outro lado, as professoras, de certa forma, também produziram um obscurecimento dos processos de alfabetização, conferindo maior destaque às práticas de letramento.

Diante da solicitação para listarem conteúdos abordados no processo de formação que, mais diretamente, orientam sua prática atual, as professoras atribuíram pequena relevância para questões relacionadas à apropriação do sistema de escrita alfabética. Como explicitado anteriormente, dentre as 1.002 participantes do estudo, obtivemos um total de 1.410 indicações, sendo baixíssima a frequência de atividades e/ou conteúdos orientadores, que dialogam com questões teórico-práticas e especificidades da alfabetização: 01 professora afirma ser necessário entender $\mathrm{o}$ processo de aprendizagem (0,09\%); 02 sinalizaram para a reflexão acerca do ciclo de alfabetização $(0,19 \%)$; 03 indicam atividades para desenvolver a consciência fonológica (0,29\%); 06 apontam a apropriação do sistema de escrita alfabética (0,59\%); e 06 outras pontuam atividades para desenvolver os níveis de escrita $(0,59 \%)$.

Ao analisar respostas relativas às atividades e metodologias sugeridas pelo PNAIC, que as professoras acreditam que continuarão a desenvolver, após o encerramento da formação continuada, novamente, identificamos um obscurecimento da alfabetização. É baixo o número de respostas indicativas de atividades para apropriação do sistema de escrita alfabética, apenas $22(2,19 \%)$, sendo outras $89(8,88 \%)$ voltadas para o desenvolvimento da consciência fonológica - índices pouco expressivos dada a relevância da alfabetização.

Os dados obtidos sinalizam a necessidade de se produzir mediações pedagógicas capazes de superar as práticas tradicionais de memorização e facilitar a apropriação do sistema de escrita alfabética pelas crianças. Contrariamente ao período anterior à década de 1980, hoje dispomos de conhecimentos que possibilitam compreender as construções 
das crianças e produzir intervenções. Ferreiro e Teberosky (1985) nos permitiram compreender que, antes de serem introduzidas no processo sistemático de aprendizagem da leitura/escrita, as crianças elaboram hipóteses, buscando ativamente se apropriar desse objeto de conhecimento. Para as autoras, os métodos tradicionais de alfabetização partem de uma visão duplamente errônea. De um lado, entendem a escrita como habilidade motora da mão (para escrever) e perceptiva do olho (para reconhecer letras); de outro lado, negam a possibilidade de a criança produzir conhecimentos.

Bellés (2001) lembra que aquisição e apropriação são duas expressões utilizadas para abordar a construção da escrita, posto que evidenciam o caráter ativo do sujeito para buscar a posse de um objeto de conhecimento. Assim, a apropriação do sistema de escrita é entendida como recriação, reconstrução cognitiva e pessoal de um objeto cultural. Ainda conforme a autora, quando se fala em apropriação da escrita, o processo não deve ser considerado como incorporação de um objeto pré-fabricado, posto que se constitua como um processo evolutivo, mas não cronológico, pelo qual a criança precisa responder as seguintes questões: para que serve escrever? o que se escreve? o que a escrita representa? como se escreve?

Sem esse conhecimento por parte das professoras, corre-se o risco de um apego excessivo à tradição de uso de métodos sintéticos de alfabetização, em práticas mecânicas e memorísticas, que lidam com unidades não significativas da linguagem e enfatizam a decifração de palavras, com prejuízo para a efetiva alfabetização e letramento das crianças.

Em nosso estudo esperava-se que as professoras conferissem relevância para conteúdos e/ou atividades voltados para compreensão do sistema de escrita alfabético e desenvolvimento de habilidades metalinguísticas, que propiciem a reflexão de forma consciente sobre a linguagem. Diferentes estudos já demonstraram a correlação positiva entre estas duas variáveis - habilidades metafonológicas e sucesso na alfabetização. Mesmo entre os defensores de abordagens construtivistas ou socioconstrutivistas, já há um reconhecimento de que a capacidade de refletir conscientemente sobre segmentos sonoros das palavras seja essencial para a alfabetização.

Conforme Leite e Morais (2012), atingir a hipótese silábica quantitativa (sem valor sonoro), pressupõe considerar a sequência de partes sonoras, esquecendo as características dos objetos a que as palavras se referem; para usar uma hipótese silábica qualitativa ou hipóteses silábico-alfabéticas e alfabéticas, as crianças precisam avançar em suas habilidades de analisar as palavras em sua pauta sonora, identificar e produzir 
palavras que começam com a mesma sílaba ou rimam. Para escrever alfabeticamente, é preciso identificar palavras que começam com o mesmo fonema, mesmo que não sejam capazes de pronunciá-lo isoladamente.

No âmbito do PNAIC, a reflexão fonológica é inerente ao processo de alfabetização e letramento. Ao discutir a evolução destes conceitos, Soares (2004) considera que, a partir da década de 1980, por um movimento paralelo à invenção da palavra letramento e dos sentidos a ela atribuídos, ocorreu a desinvenção da alfabetização. A autora entende que, no Brasil, há um enraizamento do conceito de letramento no conceito de alfabetização. No entanto, esta aproximação, ainda que para propor diferenças, tem levado a uma concepção equivocada em que se confundiu, mesclou e fundiu os dois fenômenos. Ainda conforme a autora, nessa inconveniente fusão dos dois processos tem ocorrido a prevalência do conceito de letramento e um certo apagamento da alfabetização (SOARES, 2004).

Soares (2004) entende que em períodos anteriores à década de 1980, ocorreu uma excessiva especificidade da alfabetização, entendida como autonomização das relações entre o sistema fonológico e o sistema gráfico em relação às demais aprendizagens e comportamentos na área da leitura e da escrita. No entanto, "o que parece ter acontecido, ao longo das duas últimas décadas, é que, em lugar de se fugir a essa 'excessiva especificidade', apagou-se a necessária especificidade do processo de alfabetização" (2004, p. 09, grifo da autora).

Ao reconhecer a necessária mudança paradigmática - da concepção behaviorista, que orientava as práticas alfabetizadoras tradicionais, para a concepção cognitivista, que orienta as abordagens ditas construtivistas -, Soares (2004) pontua alguns equívocos e falsas inferências, que geraram o obscurecimento do processo de aquisição do sistema convencional de escrita alfabética e ortográfica pelas práticas de letramento. A esses equívocos e falsas inferências, acrescentou-se o também decorrente falso pressuposto, “ de que apenas através do convívio intenso com o material escrito que circula nas práticas sociais, ou seja, do convívio com a cultura escrita, a criança se alfabetiza" (SOARES, 2004, p. 11).

Nas discussões sobre a questão, encontram-se posições opostas e excludentes, que precisam ser equilibradas pelo alfabetizar letrando. De um lado, a focalização excessiva sobre as especificidades da alfabetização produz resultados limitados para os aprendizes, que são capazes de decifrar o escrito, mas não são leitores plenos, que se beneficiam desta tecnologia e usufruem dos conhecimentos advindos do saber ler e 
escrever. Em outras palavras, são alfabetizados, mas não letrados; aprenderam a ler e escrever, mas o fazem de maneira limitada e pouco eficiente. Por outro lado, encontrase o obscurecimento da alfabetização, com prevalência do letramento sobre a apropriação do sistema de escrita, alicerçado na crença de que a imersão na cultura escrita seja suficiente para que as crianças aprendam a ler e escrever.

\section{Considerações finais}

Ao tomar a cultura escolar como categoria de análise, procuramos ultrapassar o nível das regulamentações e normas, das orientações e proposições do PNAIC, para compreender sua materialidade nas práticas escolares, tomando como referência os sujeitos que produzem essa cultura.

No âmbito da Unimontes, a leitura deleite integrou os seminários como estratégia formativa, alcançando centralidade nas práticas das professoras. As diferentes formas pelas quais o texto literário foi acessado nos processos de formação do PNAIC visavam à adesão das professoras ao mundo da escrita ficcional, constituindo-as como fruidoras da arte literária, de forma que, sensibilizadas para o prazer de ler, pudessem criar condições para a escola se configurar como espaço de encontro entre leitores e livros, para constituir a leitura literária como prática cotidiana, junto aos alunos em processo de alfabetização.

Os seminários também focalizaram a aquisição da leitura e da escrita pelas crianças, como processo paralelo e complementar à leitura de diferentes gêneros textuais, dado o indissociável imbricamento entre alfabetização e letramento. Apesar de altamente positivo, o trabalho com a leitura deleite não avançou para além da fruição e do prazer de ler. Outrossim, mesmo recorrente e sistematicamente abordados nos processos formativos, os conteúdos relativos à compreensão do sistema de escrita, ao desenvolvimento da consciência fonológica e às atividades de metalinguagem não se integraram à cultura escolar.

O estudo nos permitiu perceber que a formação continuada necessita de uma atenção diferenciada, por envolver saberes, sentimentos e comportamentos profissionais e pessoais das professoras, como o prazer ou o desinteresse em ser e estar docente. As análises indicam a relevância do PNAIC para a modificação das práticas pedagógicas. O tempo de formação, até o momento de 5 semestres, pode ser considerado longo, mas 
ainda se mostrou insuficiente para consolidar as mudanças necessárias. Os discursos das professoras indicam importantes transformações em suas práticas. No entanto, a instauração de mudanças mais profundas nas culturas escolares demanda um tempo maior, para convencimento, quebra de resistências, aprofundamento de estudos, vivências e experiências capazes de convencer as professoras sobre a necessidade de revisão dos saberes constituídos, experimentação das novidades e constatação dos resultados que essa renovação é capaz de produzir.

\section{Referências}

ALBERGARIA, Lino. Literatura e escola. Revista Presença Pedagógica. v. 06. n. 36. nov/dez/2000. Belo Horizonte: Dimensão, 2000.

ALVES-MAZZOTTI, Alda Judith. Representações Sociais: aspectos teóricos e aplicações à Educação. In: EM ABERTO, ano 14, n.61. Brasília: Ministério da Educação, jan./mar.1994.

BELLÉS, Rosa M. O que as crianças pequenas sabem sobre a escrita? In: PÉREZ, Francisco Carvajal; GARCIA, Joaquim Ramos (orgs). Ensinar ou aprender a ler e a escrever. Porto Alegre: Artmed, 2001. 65-84

BRASIL. Formação do Professor Alfabetizador: Apresentação - Pacto Nacional pela Alfabetização na Idade Certa. MEC, Secretaria de Educação Básica. Diretoria de Apoio à Gestão Educacional. Brasília: MEC, SEB, 2012a.

BRASIL. Pacto Nacional pela Alfabetização na Idade Certa: Formação de Professores no Pacto Nacional pela Alfabetização na Idade Certa. MEC, Secretaria de Educação Básica. Diretoria de Apoio à Gestão Educacional. Brasília: MEC, SEB, $2012 b$.

BRITO, Luiz Percival de Leme. Letramento e alfabetização: implicações para a Educação Infantil. In: FARIA, Ana Lúcia Goulart de; MELLO, Suely Amaral (Org). O mundo da escrita no universo da pequena infância. São Paulo: Autores Associados, 2007.

FERREIRA, Andrea Teresa Brito. Formação de professores: princípios e estratégias formativas. In: BRASIL. Pacto Nacional pela Alfabetização na Idade Certa. MEC, Secretaria Educação Básica. Diretoria Apoio à Gestão Educacional. Brasília: MEC, SEB, 2012

JOVECHELOVITCH, Sandra. Vivendo a vida como os outros: intersubjetividade, espaço público e Representações Sociais. In: GUARESCHI, Pedrinho, JOVCHELOVITCH, Sandra (org.). Textos em Representações Sociais. 5.ed. Petrópolis: Vozes, 1995. 
JULIA, Dominique. A Cultura escolar como objeto histórico. Revista Brasileira de História da Educação. SBHR. Campinas-SP: Editora e Autores Associados. Jan/jun/2001.

NEITZEL, Adair Aguiar. Prosa e poesia na literatura infantil: a literatura pede passagem. In: FERREIRA, Valéria Silva (orgs). Infância e linguagem escrita. Itajaí: Univale, 2007.

SOARES, Magda. Letramento e alfabetização: as muitas facetas. Revista Brasileira de Educação. Jan /Fev /Mar /Abr, no 25, p. 5-17. 2004.

VIDAL, Diana Gonçalves. O exercício disciplinado do olhar: livros, leituras e práticas de formação docente no Instituto de Educação do Distrito Federal (1932-1937). Bragança Paulista: Editora da Universidade de São Francisco, 2001.

AGRADECIMENTOS: Fundação de Amparo à Pesquisa de Minas Gerais/FAPEMIG.

\section{Como citar este artigo:}

VELOSO, Geisa Magela et al. Leitura deleite como ancoragem para mudanças pedagógicas no âmbito do PNAIC. Revista Ibero-Americana de Estudos em Educação, Araraquara, v.12, n.1, p. 404-421, 2017. Disponível em: <http://dx.doi.org/10.21723/riaee.v12.n1.8914>. E-ISSN: 1982-5587.

Data de submissão: set/2016

Aprovação final: jan/2017 